
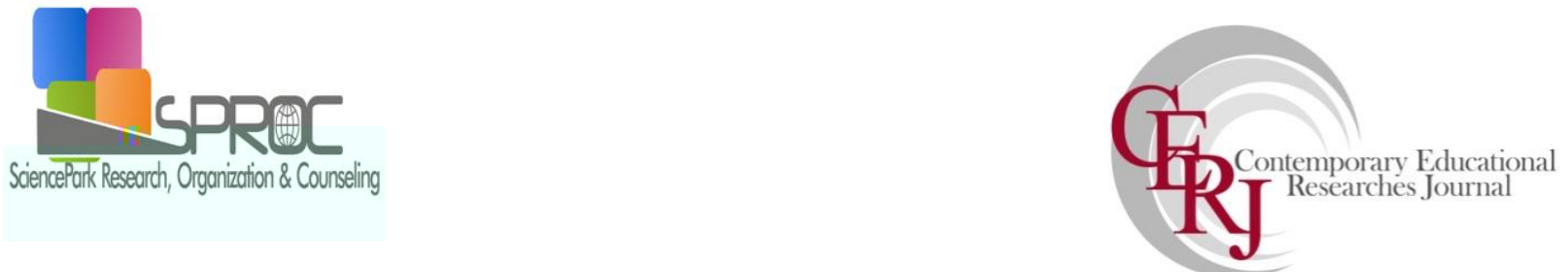

$\underline{\text { www.cerj.eu }}$

\title{
Perspectives of students - Future natural sciences teachers regarded teacher's role as educator
}

Orce Mitevski*, Mitevska Petrusheva, Katerina Biljana Popeska,

Suggested Citation:

\author{
Contemporary Educational Researches Journal 7
}

Abstract

Orce Mitevski,

E-mail address 


\section{Introduction}


Contemporary Educational Researches Journal 7 
2. Methods and materials

\section{Results and Discussion}

3.1. Educational role of the teacher 

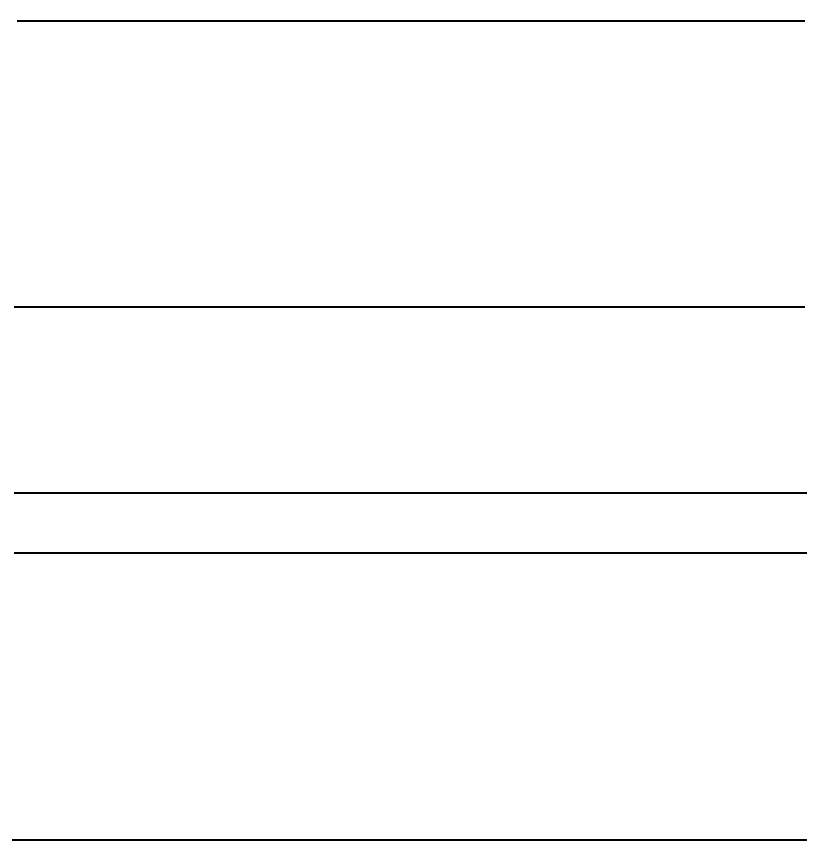
The teacher is obliged to influence educational only in certain problematic situations

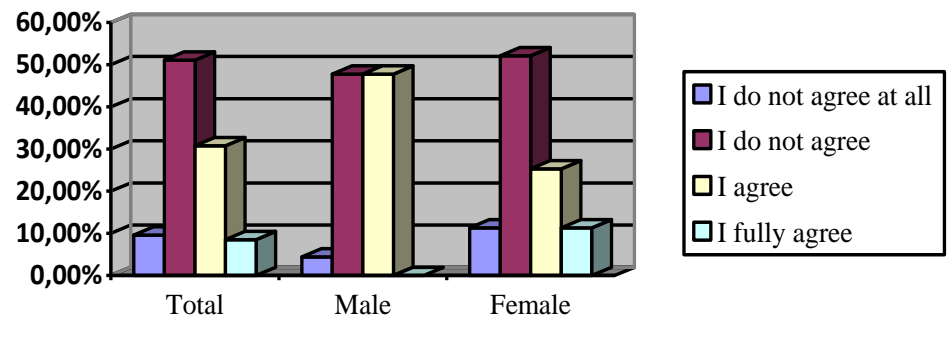




\subsection{Personal characteristics of the teacher as a factor for realization of the educational role}

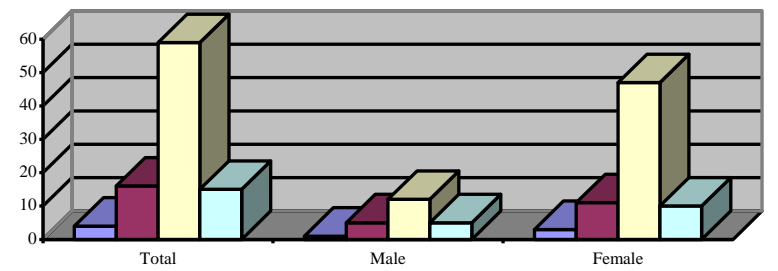

\begin{tabular}{|l|}
\hline $\mathbf{D}$ I do not agree at all \\
$\mathbf{D}_{\text {I do not agree }}$ \\
$\mathbf{D}_{\text {I agree }}$ \\
$\mathbf{D}$ I fully agree
\end{tabular}

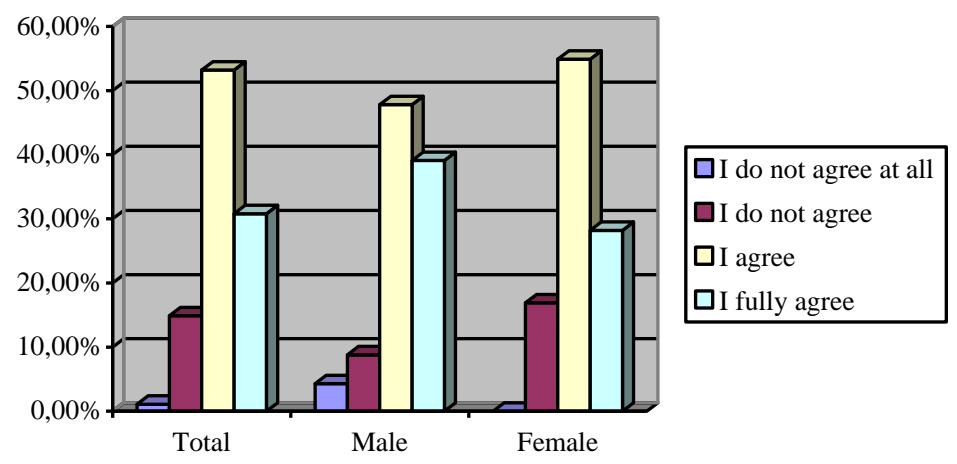


Do you consider that the social reputation of the teacher is important from the aspect of his educational role and why?

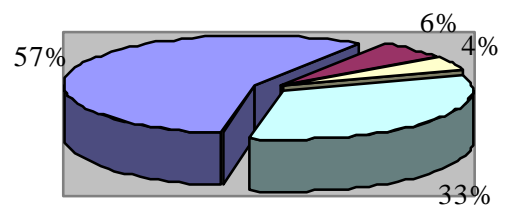

$\square$ It is important

$\square$ It is not important

$\square$ Partially important

$\square$ No answer 


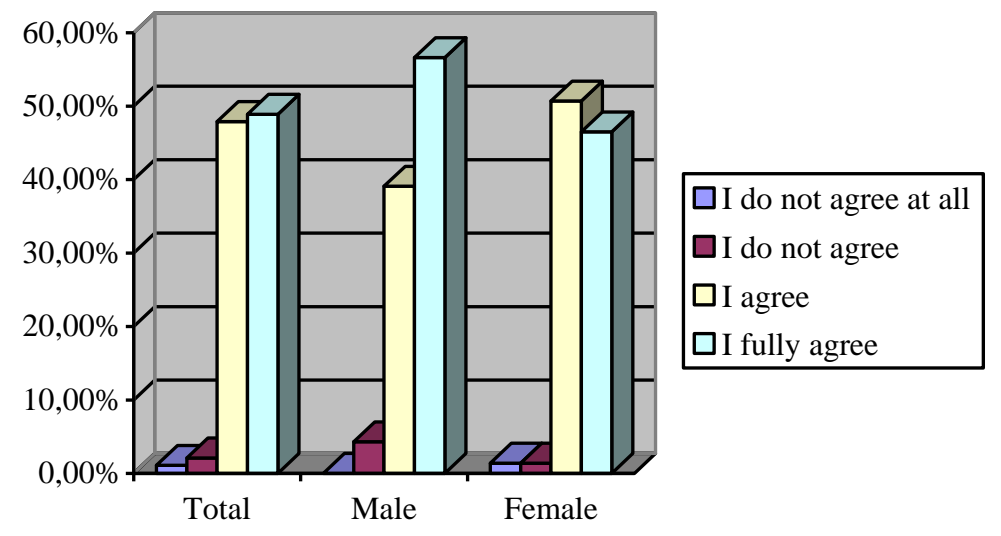

3.3. Differences in students' attitudes upon the opinion for educational role based on the gender

\section{Conclusion}




\section{References}

Ten Tips for Classroom Management

$P$

A Study of Student's Disruptive Behaviors and a Lack of Respect for Authority and peers with Middle School Students

The Education We Want (2015) UNESCO

How to be a successful teacher

Classroom Management: Techniques, Policies, Procedures, and Programs to Ensure that Discipline "Rules"in Your Classroom

Initial education of the teachers in function of realization of educational role

44

Research in Kinesiology,

Reclaiming Children and Youth, 21 